\title{
The Perception of Urban Residents on Creation and Management of Community Gardens
}

\author{
$\mathrm{Na}$ Ra Jeong", Kwang Jin Kim, Hyung Gewon Yun, Seung Won Han, and Soojin You \\ Urban Agriculture Division, National Institute of Horticultural \& Herbal Science, RDA, Wanju 55365, South Korea
}

\section{ABSTRACT}

This study analyzed the factors affecting urban residents' expectations and participation in community gardens to present basic data of guidelines for community garden management. Urban citizens valued the necessity of community gardens overall, especially residents with outdoor gardens. The experience of private gardens was important in perceiving the need for community gardens, which are public spaces. The creation of community gardens had high expectations for social aspects such as improving quality of life, health promotion, and community revitalization. In particular, residents living in individual housing have high expectations for revitalization of the community, and community gardens can be a mediator for forming and maintaining local communities. Through this, the citizens' perception on the role and function of the garden as a community space could be examined. Expectations for quality of life, health promotion, and community revitalization are factors affecting the necessity of community garden. Participation was high in the creation and management of the community garden, and the necessity of community gardens, expectation for community revitalization, and expectation for environmental purification are factors that affect participation in the management of community gardens. The amount of donations that the residents are willing to pay for community garden management was KRW 75,222 /year on average. Overall, residents with higher need for community gardens and higher social expectation showed higher participation. Urban citizens have high expectations for community gardens, and they perceive the importance of social aspects more than personal aspects such as community revitalization and quality of life. As a strategy for increasing community involvement, it is necessary to set up the processes, determine participants' composition and roles, and establish a system to promote participation. Considering welfare aspects such as community revitalization and improvement of residents' quality of life, motivation and administrative support for participation in the creation and management of community gardens will serve as important factors.

Keywords: community revitalization, donation, participation

\section{Introduction}

In the modern society, the development of transportation and communication has expanded the geographic area and turning the society into a community focused on social relations that pursue the same interests or goals. Nonetheless, actual interactions are made with focus on local communities, and thus the importance of region-based local communities is still being emphasized (Lim and Kim, 2019).
A local community can be formed by interactions focused on the residential environment. A residential environment is an important local community environment that encompasses not only physical elements such as facility accessibility or convenience but also green space in the neighborhood or relationship with neighbors (Choi and Jun, 2017; Lim et al., 2015). In other words, the physical environment of a local community is a key factor that affects the community, and thus negative perception about the environ-

This study was supported by the research project of the Rural Development Administration (PJ012581032019).

Received: September 3, 2019, Revised: September 19, 2019, Accepted: October 8, 2019

First author: Na Ra Jeong, jnr202@korea.kr, (1) https://orcid.org/0000-0002-0235-1424

*Corresponding author: Na Ra Jeong, jnr202@korea.kr, (1D https://orcid.org/0000-0002-0235-1424 
ment has a negative impact on community spirit as well (Jung, 2017).

A community garden, which is a public space in a local community, is a green space shared by many people that creates an opportunity for them to participate in the local community and can be used as a place to recover the village community as well. A community garden contributes to aesthetic improvement and crime reduction using the neglected or abandoned land in the area and has the effect of promoting local activities of residents, while also providing opportunities for the elderly and the weak that are likely to be socially neglected to participate in social activities. Furthermore, it can also be used as a place to educate children and adolescents and has many other effects such as enhancing regional value (Alaimo et al., 2008; Hynes and Howe, 2004; Litt et al., 2011; Maller et al., 2006; McCabe, 2014; Saldivar-Tanaka and Krasny, 2004; Zick et al., 2013).

The community space formed inside a regional environment can be maintained based on the community spirit of its members. Community spirit is a psychological construct that people have as social beings, based on the sense of belonging, bond or fellowship felt within a group, a community or an organization (Choi and Jeong, 2015; Lee, 2009; McMillan and Chavis, 1986). This may induce resident participation and support, thereby bringing regional development (D.G. Kim, 2011; Yang and Kang, 2008; Yim, 2005).

Overseas studies have approached the motives for participating in community gardens in the functional aspect (Armstrong, 2000; Birky and Strom, 2013; Guitart et al., 2012; Poulsen et al., 2014). At first, people participated in community gardens due to their need for food ingredients, but as time passed their motives are changing into more diverse reasons aside from food production (Birky and Strom, 2013). Other motives for participating in community gardens include leisure and recreational activities (Nordh et al., 2016: Scott et al., 2018) and expectations for improvement of psychological and physical health (Poulsen et al., 2014; Schram-Bijkerk et al., 2018). Other studies explain the growing interest in social interaction (Poulsen et al., 2017; Saldivar-Tanaka and Krasny, 2004). Moreover, studies from the emotional perspective emphasize that the key motive for participating in gardening is attachment to the community garden, and that resi- dents' emotions toward the garden increase their will to participate (Birky and Strom, 2013; Nordh et al., 2016). In terms of individual attributes of participants, studies have been conducted on their participation due to diverse needs and motives, such as socioeconomic characteristics of residents, gardening experience, skills and knowledge, and accessibility to the community garden (Bell et al., 2016; Birky and Strom, 2013; Partalidou and Anthopoulou, 2017; Winkler et al., 2019). In other words, studies on the relevance between motivation and participation showed that residents with diverse and richer experience in gardens showed a high level of participation in the community garden (Drake and Lawson, 2015) and had a high level of subjective happiness (Mourão et al., 2019).

However, studies in Korea were conducted on the direction for creating and planning community gardens, preferences, and effects. There have been studies on the spatial, social and psychological effects of community gardens (Kim, 2013; Kim and Cho, 2010; Kim and Lee, 2013; Roh, 2012), model development and planning (Choi and Seo, 2016; Jeong, Han, Kim, and Jung, 2018; M.H. Kim, 2011; Oh and Park, 2015), garden creation as a strategy for community revitalization (Han and Nam, 2015; Kang et al., 2013), and direction for creation (Jeong, Han, Kim, Suh, and Yoon, 2018). However, research on community management and participation is insufficient compared to overseas. Studies have not been conducted on resident participation from creation to management of community gardens.

This study is conducted to determine the perception of urban residents about participating in creation and management activities of community gardens that are presented as an alternative for urban regeneration and community revitalization and provide baseline data for community creation and management guidelines. To this end, we intended to determine the effects on participation in planning, constructing and managing community gardens.

\section{Research Methods}

\section{Hypothesis setting}

This study is aimed at determining factors that affect 
participation in creating and managing community gardens. Choi and Jeong (2015) categorized resident participation by initiative into participation led by the government in the form of providing information, participation led by residents, and cooperative participation with a two-way relationship between the government and residents. Cho (2008) classified it by process into policy, planning and management aspects. This study examined the perception of urban residents about participation in terms of planning and management in the process of creating community gardens.

Research hypotheses are set up to analyze the factors affecting participation in community gardens. Yang and Kang (2008) proved that higher fulfillment in community activities leads to more resident participation. As this study is on the perception of urban residents, participation will vary depending on the perception gap about community gardens by expanding fulfillment to expectation and necessity. Based on the above, we set Hypothesis 1 as 'Participation may vary depending on expectation and necessity about community gardens'. Moreover, overseas studies explain that participation in community gardens varies depending on motivation and user characteristics. Residence type and garden experience particularly affect the perception gap about participating in community gardens. Thus, we set Hypothesis 2 as 'Participation in community gardens may vary depending on the demographic characteristics of urban residents'.

\section{Questionnaire structure}

To test the hypotheses, we conducted a survey for data collection and developed survey items based on literature review. Necessity of community gardens was rated on a 5-point Likert scale ( $1=$ not necessary at al; 5=highly necessary). To measure expectation for community gardens, we analyzed the findings of previous studies on the effects and functions of community gardens and developed items in 5 types: environmental, economic, psychological, physical, and social aspects (Table 1). Expectation for creating a community garden is rated on a 5-point Likert scale ( $1=$ no expectation at all; 5=high expectation), with items such as village environmental improvement in the environmental aspect, revitalization of individual and regional economy in the economic aspect, improvement of quality of life in the psychological aspect, health promotion in the physical aspect, and community revitalization in the social aspect. To determine internal consistency of items, a preliminary study is conducted to analyze Cronbach's alpha, which turned out to be 0.846 and proved relatively high reliability.

Participation in community gardens is classified into planning, construction, management and education, and we developed the questionnaire so that participation for each stage is rated on a 5-point Likert scale. Moreover, items on participation in fundraising for management and budget for participation intention are set up as open-ended questions.

\section{Data collection method}

To determine the perception of people living in the city where community gardens are mostly created, we conducted the survey on urban residents. We assumed that urban residents who participated in exhibitions related to urban agriculture or gardens may be more interested in gardening and kitchen gardens than others, and thus we conducted the survey on the participants of garden fairs and

Table 1. Effects and function of community garden mentioned in the literature

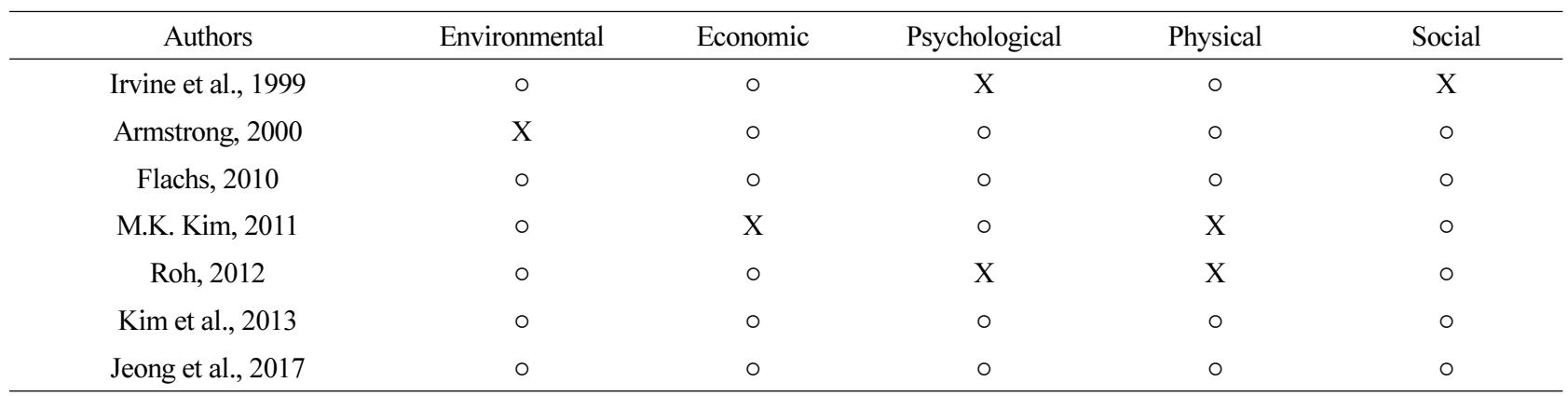


urban agriculture exhibitions. We randomly distributed the questionnaire to 600 people who attended Seoul Garden Show 2017 and 2018, Urban Agriculture Exhibition in Busan 2019, and Korean Urban Agriculture Expo 2019. We analyzed 580 copies excluding those with insincere responses. We distributed the questionnaire and had the respondents fill it out to minimize the influence of researchers.

\section{Analysis method}

\section{Analysis method}

This study conducted statistical analysis using SPSS 25 Package. For expectation about community gardens, we conducted t-test and ANOVA to test the significance according to demographic attributes. Linear regression analysis was conducted to determine factors affecting necessity and participation by quantifying them into scores. Necessity (dependent variable) is converted into 5 points, and its relationship with expectation (independent variable) was analyzed. For participation, we rated the participation in each stage of planning, construction and management of community gardens on a 3-point scale, set the dependent variables with the sum of participation of the three stages, and analyzed its relationship with expectation. Moreover, we conducted logistic regression analysis to determine and predict whether urban residents' perception bout community gardens affect participation. Since it nonlinearly depicts the relations between dependent and independent variables, it is a suitable method for predicting or analyzing nonlinear characteristics such as participation and need of urban residents. This study estimated the causal relation between necessity of community gardens and expectation for community gardens in relation to participation using logistics relationships. Binary categories of necessary and unnecessary were used for necessity (dependent variable) of community gardens and participation and non-participation for participation (dependent variable). Expectation (independent variable) is analyzed using a 5-point Likert scale. Linear regression analysis is used to determine factors that have effect in the quantitative aspect, and logistic regression analysis is used to analyze the causal relations in terms of qualitative aspect of categories.

\section{Measurement variables}

The dependent and independent variables used in this study are as follows (Table 2), and the measures for necessity, par-

Table 2. Setting and measuring variables

\begin{tabular}{|c|c|c|c|}
\hline \multicolumn{3}{|c|}{ Variables } & Variable value \\
\hline \multicolumn{3}{|c|}{ Necessity of community gardens } & 5-point Likert scale \\
\hline \multirow{5}{*}{$\begin{array}{c}\text { Dependent } \\
\text { variable }\end{array}$} & \multicolumn{2}{|c|}{ Whether you need a community garden } & No need $=0$, need $=1$ \\
\hline & \multicolumn{2}{|c|}{ Participation in community gardens } & 2 point Likert scale \\
\hline & \multicolumn{2}{|c|}{ Whether to participate in a community garden } & No participation $=0$, participation $=1$ \\
\hline & \multicolumn{2}{|c|}{ Donation amounts for management } & Open-ended \\
\hline & \multicolumn{2}{|c|}{ Whether to participate in fundraising } & No participation $=0$, participation $=1$ \\
\hline \multirow{11}{*}{$\begin{array}{c}\text { Independent } \\
\text { variable }\end{array}$} & \multirow{7}{*}{ Expectation } & Rise in house prices & 5-point Likert scale \\
\hline & & Improvement of quality of life & 5-point Likert scale \\
\hline & & Community revitalization & 5-point Likert scale \\
\hline & & Health promotion & 5-point Likert scale \\
\hline & & Village environmental purification & 5-point Likert scale \\
\hline & & Increasing visit frequency & 5-point Likert scale \\
\hline & & Local economy activation & 5-point Likert scale \\
\hline & \multicolumn{2}{|l|}{ Age } & $20-30 \mathrm{~s}=0,40-50 \mathrm{~s}=1,60 \mathrm{~s}$ or over $=2$ \\
\hline & \multicolumn{2}{|l|}{ Gender } & Male $=0$, female $=1$ \\
\hline & \multicolumn{2}{|c|}{ Owning outdoor garden } & $\mathrm{No}=0, \mathrm{yes}=1$ \\
\hline & \multicolumn{2}{|l|}{ Housing type } & Single-home $=0$, apartment $=1$ \\
\hline
\end{tabular}


ticipation, fundraising, etc. in dependent variables are readjusted according to the characteristics of regression analysis.

\section{Results and Discussion}

\section{Analysis on expectation for community gardens}

\section{Expectation for community gardens}

As a result of rating expectation for community gardens on a 5 -point scale $(5=$ high expectation; $3=$ neutral; $1=$ no expectation at all), it was found that expectation was high for improvement of quality of life, health promotion, friendship revitalization in the community, and village environmental purification, whereas it was low for increase in visit frequency and revitalization of regional economy. Overall, expectation is high in terms of individuals, but the participants did not seem interested in visits of other people in the village or revitalization of regional economy (Table 3).

Analysis on the difference in expectation by age showed that older age groups showed higher expectation overall, whereas expectation for improvement of quality of life did not show statistically significant difference. In other words, residents are expecting quality of life to improve by creating community gardens regardless of age. The participants in their 20-30s showed lower expectation than other age groups in all items except satisfaction in quality of life. They gave relatively lower scores to expectation items such as increase in visit frequency, revitalization of regional economy, and increase in housing prices. This is because the expectation items do not have direct effect on ages 20-30s or do not attract their interest, whereas quality of life is directly related to their individual purpose, thereby higher than other age groups. Participants in their 60s and older generally gave high scores to expectation than other age groups, which is because they have lived in the region for a longer time than other age groups and have relatively higher community spirit (Chung et al., 2015), thereby showing high expectation for community gardens.

By gender, women showed higher expectation overall in most items compared to men, and the ranking also varied by gender. As pointed out by Conway and Hachen (2005), this suggests that women who spend more time in the region show high expectation. This is because men spend less time near their residence since they show higher frequency of socioeconomic activities to earn income than women. Expectation for community revitalization did not show statistically significant difference, which suggests that both men and women expect their community to be revitalized by community gardens. Overall, both men and women had high expectation for health promotion, excluding improvement of quality of life that showed high expectation overall. This indicates that they have high expectation for community gardens as a space for leisure activities to promote physical and mental health, which may be a factor that can lead to participation in community gardens.

In general, those who responded that community gardens are necessary showed high expectation with statistically

Table 3. Expectation for community gardens by age and gender

\begin{tabular}{|c|c|c|c|c|c|c|c|c|c|}
\hline \multirow{2}{*}{ Criterion } & \multicolumn{2}{|c|}{ Expectation } & \multicolumn{4}{|c|}{$\mathrm{Age}^{\mathrm{z}}$} & \multicolumn{3}{|c|}{ Gender } \\
\hline & M & SD & $20-30 \mathrm{~s}$ & $40-50 \mathrm{~s}$ & 60 s or over & $\mathrm{F}$ & Female & Male & $\mathrm{t}$ \\
\hline Rise in house prices & 3.85 & 0.89 & $3.52 \mathrm{~b}$ & $4.04 \mathrm{a}$ & $4.13 \mathrm{a}$ & $16.14 * *$ & 3.95 & 3.56 & $3.05 * *$ \\
\hline Improvement of quality of life & 4.31 & 0.69 & 4.22 & 4.37 & 4.15 & 2.44 & 4.32 & 4.10 & $2.41^{*}$ \\
\hline Community revitalization & 3.96 & 0.84 & $3.73 b$ & $4.12 \mathrm{a}$ & $4.11 \mathrm{a}$ & $8.05 * *$ & 3.97 & 3.93 & 0.38 \\
\hline Health promotion & 4.12 & 0.76 & $3.94 \mathrm{~b}$ & $4.29 \mathrm{a}$ & $4.32 \mathrm{a}$ & $8.58 * *$ & 4.22 & 4.00 & $2.23^{*}$ \\
\hline Village environmental purification & 3.91 & 0.89 & $3.58 \mathrm{~b}$ & $4.23 \mathrm{a}$ & $4.08 \mathrm{a}$ & $8.05^{* *}$ & 4.02 & 3.66 & $2.95 * *$ \\
\hline Increasing visit frequency & 3.31 & 1.08 & $2.88 \mathrm{c}$ & $3.50 \mathrm{~b}$ & $3.92 \mathrm{a}$ & $29.31 * *$ & 3.41 & 3.13 & $2.00^{*}$ \\
\hline Local economy activation & 3.66 & 0.99 & $3.38 \mathrm{~b}$ & $3.80 \mathrm{a}$ & $4.00 \mathrm{a}$ & $11.67 * *$ & 3.76 & 3.44 & $2.19^{*}$ \\
\hline
\end{tabular}

Note. 5-point Likert scale was used to rate expectations.

${ }^{\mathrm{z}}$ Different letters denote significant differences.

${ }^{*} p<.05,{ }^{* *} p<.01$. 
significant difference. In terms of residential housing type, participants living in individual housing showed relatively high expectation for community revitalization, health promotion, and village environmental purification, while those living in apartments showed relatively high expectation for increase in housing prices and improvement of quality of life (Table 4). Those living in individual housing perceived public interests important, such as community revitalization and village environmental improvement, compared to those living in apartments. However, the latter showed more interest in the economic aspect as a privately-owned space. Analysis on the difference in expectation according to residential type showed that there was no statistically significant difference except community revitalization. As discovered in various studies, residents of individual housing showed high expectation for local community revitalization through community gardens. Those who own an outdoor garden showed higher expectation overall than those who do not, but there was no statistically significant difference. Participants not owning an outdoor garden had high expectation for health promotion, perceiving that gardens can contribute to promoting their health. When creating a community garden, some ways to increase participation would be to create spaces and manage programs that reflect these expected outcomes.

\section{Necessity of community gardens}

\section{Necessity of community gardens}

As a result of rating necessity of community gardens on a 5 -point scale (5=highly necessary; $3=$ neutral; $1=$ not necessary at all), necessity was high with the mean of 4.16 (Table 5). By age, there is a statistically significant difference, with older age showing higher necessity, and those in their 20-30s show lower necessity than other age groups. Participants with an outdoor garden showed higher necessity with statistically significant difference. This was similar to the result of previous research (Chalise, 2015) that people who experienced gardening showed high participation in community gardens, even though interest in community gardens does not directly lead to actual participation. Positive experience in private gardens seemed to have performed a key role in perceiving the necessity of public gardens. By residential type and gender, participants living in individual housing and women showed relatively higher

Table 4. Expectation for community gardens by necessity, housing type, and owning outdoor garden

\begin{tabular}{|c|c|c|c|c|c|c|c|c|c|}
\hline \multirow{2}{*}{ Criterion } & \multicolumn{3}{|c|}{ Necessity of community gardens } & \multicolumn{3}{|c|}{ Housing type } & \multicolumn{3}{|c|}{ Outdoor garden } \\
\hline & Need & No need & $\mathrm{t}$ & Single-home & Apartment & $\mathrm{t}$ & Owning & Not owning & $\mathrm{t}$ \\
\hline Rise in house prices & 3.93 & 3.48 & $3.28 * *$ & 3.78 & 3.88 & -0.73 & 3.92 & 3.73 & 1.73 \\
\hline Improvement of quality of life & 4.34 & 3.71 & $6.13^{* *}$ & 4.17 & 4.27 & -1.01 & 4.34 & 4.21 & 1.59 \\
\hline Community revitalization & 4.02 & 3.50 & $4.10^{* *}$ & 4.24 & 3.87 & $3.13 * *$ & 3.97 & 3.91 & 0.57 \\
\hline Health promotion & 4.23 & 3.67 & $412^{* *}$ & 4.20 & 4.14 & 0.58 & 4.25 & 4.08 & 1.92 \\
\hline Village environmental purification & 4.02 & 3.38 & $4.82 * *$ & 3.94 & 3.92 & 0.10 & 4.02 & 3.82 & 1.78 \\
\hline Increasing visit frequency & 3.41 & 3.06 & $2.28^{*}$ & 3.48 & 3.32 & 1.04 & 3.34 & 3.28 & 0.49 \\
\hline Local economy activation & 3.74 & 3.38 & $2.37 *$ & 3.62 & 3.68 & -0.25 & 3.73 & 3.61 & 0.96 \\
\hline
\end{tabular}

Note. 5-point Likert scale was used to rate expectations.

${ }^{*} p<.05,{ }^{*} p<.01$.

Table 5. Necessity of community gardens by age and owning outdoor garden

\begin{tabular}{|c|c|c|c|c|c|c|c|c|c|}
\hline \multirow{2}{*}{ Criterion } & \multicolumn{2}{|c|}{ Necessity } & \multicolumn{4}{|c|}{$\mathrm{Age}^{\mathrm{z}}$} & \multicolumn{3}{|c|}{ Outdoor garden } \\
\hline & $\mathrm{M}$ & SD & $20-30 \mathrm{~s}$ & $40-50 \mathrm{~s}$ & 60 s over & $\mathrm{F}$ & Owning & Not owning & $\mathrm{t}$ \\
\hline Necessity of community gardens & 4.16 & 0.77 & $3.84 b$ & $4.26 \mathrm{a}$ & $4.29 \mathrm{a}$ & $17.69 * *$ & 4.23 & 4.05 & $2.46^{* *}$ \\
\hline
\end{tabular}

Note. 5-point Likert scale was used to rate necessity of community gardens.

${ }^{\mathrm{z}}$ Different letters denote significant differences.

${ }^{*} p<.05,{ }^{* *} p<.01$. 
expectation, but there was no statistically significant difference.

\section{Factors affecting necessity of community gardens}

Necessity of community gardens is rated on a 5-point scale (5=highly necessary; $3=$ neutral; $1=$ not necessary at all), and expectation is also rated on a 5 -point scale $(5=$ high expectation; $3=$ neutral; $1=$ no expectation at all). Regression analysis was conducted to determine expectation factors that affect necessity. Among the variables, expectation for health promotion, improvement of quality of life, and increase in visit frequency turned out to have effect (Table 6). Relative influence was greatest in improvement of quality of life, followed by health promotion and increase in visit frequency, which have significant effects on necessity of community gardens.

\section{Factors that affect necessity of community gardens}

To determine the effect of expectation for community gardens on necessity, we conducted logistic regression analysis. The classification accuracy of the model was $86.3 \%$ and thus satisfactory. In the Hosmer-Lemeshow test, chi-square represents consistency between actual values of dependent variables and the values predicted by the model, with smaller values indicating higher goodness of fit, and the goodness of fit of this model is acceptable. Among the variables, improvement of quality of life expectation and community revitalization expectation had significant effects on necessity of community gardens (Table 7). Those expecting improvement of quality of life are 3.202 times more likely and those expecting community revitalization are 2.193 times more likely to think that community gardens are necessary. Compared to other variables, higher expectation for improvement of quality of life and community revitalization makes them more likely to think that community gardens are necessary.

\section{Participation in community gardens}

\section{Participation in community gardens}

Participation in community gardens is subdivided into stages of planning, construction, management and education to rate participation on a 5 -point scale $(5=$ active participation; $3=$ neutral; $1=$ no participation at all). Participation in management was lower than that in planning and construction, whereas participation was high in education and planning, which are more one-off and have relatively fewer activities, which indicates that people feel pressure about continuous management (Table 8). By age, participants in their 20-30s showed relatively lower participation in all stages than other age groups, especially management. Those in their 40-50s and older showed higher participation in

Table 6. Regression analysis of necessity of community gardens

\begin{tabular}{|c|c|c|c|c|c|c|}
\hline \multirow{2}{*}{ Variables } & \multicolumn{2}{|c|}{ Unstandardized coefficients } & \multirow{2}{*}{$\begin{array}{c}\text { Standardized coefficients } \\
\beta\end{array}$} & \multirow{2}{*}{$\mathrm{t}(p)$} & \multirow{2}{*}{$\mathrm{F}(p)$} & \multirow{2}{*}{$\begin{array}{c}\text { Adjusted } \\
\mathrm{R}^{2}\end{array}$} \\
\hline & $B$ & $S E$ & & & & \\
\hline (Constant) & 1.997 & 0.283 & & $7.066(.000)$ & \multirow{4}{*}{$\begin{array}{l}18.708 \\
(.000)\end{array}$} & \multirow{4}{*}{0.150} \\
\hline Expectation for health promotion & 0.187 & 0.058 & 0.190 & $3.206(.001)$ & & \\
\hline Expectation for improving the quality of life & 0.213 & 0.063 & 0.197 & $3.401(.001)$ & & \\
\hline Expectation for increasing visit frequency & 0.105 & 0.040 & 0.148 & $2.618(.009)$ & & \\
\hline
\end{tabular}

Table 7. Logistic regression analysis of necessity of community gardens

\begin{tabular}{lcccccc}
\hline \multicolumn{1}{c}{ Variables } & $\beta$ & SE & Wald & df & $p$ & Exp(B) \\
\hline Expectation for improving quality of life & 1.164 & 0.289 & 16.268 & 1 & .000 & 3.202 \\
Expectation for community revitalization & 0.785 & 0.246 & 10.190 & 1 & .001 & 2.193 \\
(Constant) & -5.897 & 1.385 & 18.118 & 1 & .000 & 0.003 \\
\hline
\end{tabular}

Note. $2 L L=175.078$, Cox \& Snell $\mathrm{R}^{2}=.140$, Nagelkerke $\mathrm{R}^{2}=.243$, Hosmer \& Lemeshow test chi $^{2}=4.053(\mathrm{df}=5, p=.542)$, Classification accuracy $=86.3 \%, \beta=$ regression coefficients, $\mathrm{SE}=$ standard error, Wald=test of significant. 
education than other age groups and lower participation in management. Those in their $60 \mathrm{~s}$ and older showed high participation in planning and low participation in education. In terms of enhancing community competence, recently there are various education programs including gardening for residents. But considering participation and effect, it is necessary to consider diversifying these programs by age group. In participation by stage, there was statistical significance in the difference by age. By gender, men showed higher participation than women overall, but there was no statistically significant difference. Men relatively seemed to have more interest in social and public aspects.

Participants claiming that community gardens are necessary showed relatively higher participation with statistically significant difference (Table 9). By residential type, those living in individual housing showed higher participation, but there was no statistically significant difference. Those with an outdoor garden showed relatively higher partic- ipation, and there was statistically significant difference in all except participation in education.

As a result of analyzing the intention to participate in fundraising to collect funds for management of community gardens, about half of the participants responded that they are willing to participate every year, and $40.9 \%$ claimed to participate once; thus, at least $90 \%$ of the participants responded that they will participate at least once (Table 10). Residents' fundraising will enable them to purchase materials, plants and fertilizers for management of community gardens.

As a result of analyzing the amount the participants can donate, it was minimum KRW 1,000 to maximum KRW 300,000, and the mean was KRW 75,222 (Table 11). There was no statistical significance by residential type, outdoor garden, need for community garden, gender and age. There are no studies on the amount participants are willing to pay for management of community gardens, but the study

Table 8. Participation in community gardens by age and gender

\begin{tabular}{|c|c|c|c|c|c|c|c|c|c|}
\hline \multirow{2}{*}{ Criterion } & \multicolumn{2}{|c|}{ Participation } & \multicolumn{4}{|c|}{$\mathrm{Age}^{\mathrm{z}}$} & \multicolumn{3}{|c|}{ Gender } \\
\hline & M & $\mathrm{SD}$ & $20-30 s$ & $40-50 \mathrm{~s}$ & 60 s or over & $\mathrm{F}$ & Male & Female & $\mathrm{t}$ \\
\hline Participation in planning & 4.06 & 0.91 & $3.77 \mathrm{~b}$ & $4.12 \mathrm{a}$ & $4.24 \mathrm{a}$ & $12.06^{* *}$ & 4.13 & 3.99 & 1.48 \\
\hline Participation in construction & 4.03 & 0.93 & $3.72 b$ & $4.14 \mathrm{a}$ & $4.19 \mathrm{a}$ & $12.57 * *$ & 4.14 & 3.95 & 1.86 \\
\hline Participation in management & 3.92 & 0.98 & $3.46 \mathrm{~b}$ & $4.08 \mathrm{a}$ & $4.12 \mathrm{a}$ & $23.77 * *$ & 3.95 & 3.86 & 0.88 \\
\hline Participation in education & 4.13 & 0.93 & $3.71 \mathrm{~b}$ & $4.27 \mathrm{a}$ & $4.07 \mathrm{ab}$ & $3.43^{*}$ & 4.31 & 4.02 & 1.94 \\
\hline
\end{tabular}

Note. 5-point scale was used to rate residents' participation.

${ }^{\mathrm{z}}$ Different letters denote significant differences.

${ }^{*} p<.05,{ }^{* *} p<.01$.

Table 9. Participation in community gardens by necessity of gardens, housing type, and owning outdoor garden

\begin{tabular}{|c|c|c|c|c|c|c|c|c|c|}
\hline \multirow{2}{*}{ Criterion } & \multicolumn{3}{|c|}{ Necessity of community gardens } & \multicolumn{3}{|c|}{ Housing type } & \multicolumn{3}{|c|}{ Outdoor garden } \\
\hline & Need & No need & $\mathrm{t}$ & Single-home & Apartment & $\mathrm{t}$ & Owning & Not owning & $\mathrm{t}$ \\
\hline Participation in planning & 4.14 & 3.62 & $4.90^{* *}$ & 4.16 & 4.02 & 1.55 & 4.14 & 3.94 & $2.28 *$ \\
\hline Participation in construction & 4.11 & 3.58 & $4.39 * *$ & 4.12 & 3.99 & 1.41 & 4.12 & 3.91 & $2.29 *$ \\
\hline Participation in management & 4.02 & 3.33 & $6.01 * *$ & 4.01 & 3.88 & 1.38 & 4.02 & 3.75 & $2.77^{* *}$ \\
\hline Participation in education & 4.19 & 3.78 & $2.03 *$ & 4.19 & 4.11 & 0.66 & 4.23 & 3.97 & 1.73 \\
\hline
\end{tabular}

Note. 5-point scale was used to rate residents' participation.

${ }^{*} p<.05, * * p<.01$.

Table 10. Participation in fundraising for management of community gardens

\begin{tabular}{ccccc}
\hline Division & Plan to participate every year & Plan to participate once & Plan not to participate & Total \\
\hline Frequency $(\%)$ & $287(50.9)$ & $235(40.9)$ & $52(9.1)$ & $574(100.0)$ \\
\hline
\end{tabular}


by An (2012) on management of urban parks estimated that the maximum amount of operational and maintenance expenses park users can pay every year is KRW 68,000. Previous research examined users within $1 \mathrm{~km}$ of the urban park for the purpose of park management, which may perform similar functions as community gardens. Considering the difference in research period, the perception of urban residents about paying for management of public space is similar.

In terms of demographics, there was no statistically significant difference in the amount the participants are willing to pay by gender, residential type and age (Table 12). Urban residents with an outdoor garden were willing to pay more with statistically significant difference. Those with outdoor gardens experienced the utility of gardens and have experience in managing them, which is why they are willing to pay more considering both utility and actual expenses. In terms of disposition, men were willing to pay more than women, and younger participants also intended to pay more. Participants in their $60 \mathrm{~s}$ and older were willing to pay relatively smaller amount, indicating that despite their high expectation for community gardens, they had lit- tle intention to pay for the benefits of public goods. There was almost no difference in the amount by residential type.

Logistic regression analysis was conducted to determine the effects of expectation and necessity of community gardens on participating in fundraising for management of community gardens. Participation in fundraising was analyzed by assuming that those who responded they will pay at least once are willing to participate. The classification accuracy of the model was $89.5 \%$, which is satisfactory, and its goodness of fit is acceptable. Among the variables, increase in visit frequency expectation and necessity of community gardens turned out to have significant effects on participation in fundraising for management (Table 13). Those expecting increase in visit frequency were 1.686 times more likely and those claiming that community gardens are necessary were 3.051 times more likely to participate in fundraising for management of community gardens. In other words, higher expectation for increase in visit frequency and necessity of community gardens makes them more likely to participate in fundraising for management of community gardens.

Table 11. Donation planning for the management of community gardens

\begin{tabular}{ccccc}
\hline Division & M \pm SD & Minimum & Maximum & Median \\
\hline Donation amount $(\mathrm{KRW})$ & $75,222 \pm 208,074$ & 1,000 & 300,000 & 30,000 \\
\hline
\end{tabular}

Table 12. Donation planning in KRW by gender, housing type, owning outdoor garden, and age

\begin{tabular}{|c|c|c|c|c|c|c|c|c|c|}
\hline \multirow{2}{*}{ Division } & \multicolumn{2}{|c|}{ Gender } & \multicolumn{2}{|c|}{ Housing type } & \multicolumn{2}{|c|}{ Outdoor garden } & \multicolumn{3}{|c|}{ Age } \\
\hline & Male & Female & Single-home & Apartment & Owning & Not owning & $20-30 \mathrm{~s}$ & $40-50 \mathrm{~s}$ & 60 s or over \\
\hline M & 75,615 & 70,687 & 75,868 & 75,774 & 94,0734 & 52,477 & 105,676 & 80,646 & 48,962 \\
\hline $\mathrm{t}$ & \multicolumn{2}{|c|}{0.202} & \multicolumn{2}{|c|}{0.004} & \multicolumn{2}{|c|}{$1.859^{*}$} & \multicolumn{3}{|c|}{-} \\
\hline $\mathrm{F}$ & \multicolumn{2}{|c|}{-} & \multicolumn{2}{|c|}{-} & \multicolumn{2}{|r|}{ - } & \multicolumn{3}{|c|}{1.971} \\
\hline
\end{tabular}

$* p<.05, * * p<.01$

Table 13. Logistic regression analysis of participation in fundraising

\begin{tabular}{lcccccc}
\hline \multicolumn{1}{c}{ Variables } & $\beta$ & SE & Wald & df & $p$ & Exp(B) \\
\hline Expectation for increasing visit frequency & 0.522 & 0.211 & 6.126 & 1 & .013 & 1.686 \\
Necessity of community gardens & 1.115 & 0.269 & 17.164 & 1 & .000 & 3.051 \\
(Constant) & -3.714 & 1.128 & 10.840 & 1 & .001 & 0.024 \\
\hline
\end{tabular}

Note. $2 L L=147.036$, Cox \& Snell $\mathrm{R}^{2}=.121$, Nagelkerke $\mathrm{R}^{2}=.235$, Hosmer \& Lemeshow test chi $^{2}=4.774(\mathrm{df}=7, p=.687)$, Classification accuracy $=89.5 \%$. 


\section{Factors affecting participation in community gardens}

Regression analysis was conducted with participation such as planning, construction and management of community gardens as dependent variables, and expectation as the independent variables, thereby determining factors of expectation that affect participation. Variables that affect participation in planning were expectation for necessity, community revitalization and increase in housing prices, with the necessity of community gardens showing the greatest impact. Variables that affect participation in construction and management were necessity, community revitalization expectation, and increase in visit frequency expectation. Similar variables affected each stage of creation, but the difference is that expectation for increase in housing prices is included as a factor affecting participation in planning. Variables that affect overall participation are necessity of community gardens, community revitalization, and village environmental purification. Relative influence was greatest in necessity of community gardens, followed by community revitalization and village environmental purification, significantly affecting participation from construction to management of community gardens (Table 14).
Participants who perceive that community gardens are necessary are more likely to participate once the gardens are created, but their interest does not lead to actual participation and thus it is necessary to seek ways to encourage active participation.

Logistic regression analysis was conducted to determine the effects of expectation and necessity on participation in community gardens. Participants who responded to only one stage among planning, construction and management were considered to have intention to participate. The classification accuracy of the model was $82.4 \%$, which is satisfactory. Among the variables, expectation for community revitalization and necessity of community gardens had significant effects on participation in community gardens (Table 15). Those expecting community revitalization are 1.757 times more likely and those claiming that community gardens are necessary are 2.209 times more likely to participate in community gardens. Compared to other variables, those with higher expectation for community revitalization and necessity of community gardens are more likely to participate in construction and management of community gardens.

Table 14. Regression analysis of participation in community gardens

\begin{tabular}{|c|c|c|c|c|c|c|c|}
\hline \multirow[t]{2}{*}{ Division } & \multirow[t]{2}{*}{ Variables } & \multicolumn{2}{|c|}{$\begin{array}{l}\text { Unstandardized } \\
\text { coefficients }\end{array}$} & \multirow{2}{*}{$\begin{array}{c}\begin{array}{c}\text { Standardized } \\
\text { coefficients }\end{array} \\
\beta\end{array}$} & \multirow[t]{2}{*}{$\mathrm{t}(p)$} & \multirow[t]{2}{*}{$\mathrm{F}(p)$} & \multirow{2}{*}{$\begin{array}{c}\text { Adjusted } \\
\mathrm{R}^{2}\end{array}$} \\
\hline & & $B$ & $S E$ & & & & \\
\hline \multirow{4}{*}{$\begin{array}{c}\text { Participation in } \\
\text { planning }\end{array}$} & (Constant) & 1.135 & 0.302 & & $3.755(.000)$ & \multirow{4}{*}{$\begin{array}{l}31.722 \\
(.000)\end{array}$} & \multirow{4}{*}{0.235} \\
\hline & Necessity of community gardens & 0.419 & 0.062 & 0.361 & $6.787(.000)$ & & \\
\hline & Expectation for community revitalization & 0.187 & 0.057 & 0.179 & $3.312(.001)$ & & \\
\hline & Expectation for rise in house prices & 0.116 & 0.052 & 0.119 & $2.230(.026)$ & & \\
\hline \multirow{4}{*}{$\begin{array}{l}\text { Participation in } \\
\text { construction }\end{array}$} & (Constant) & 0.182 & 0.304 & & $3.889(.000)$ & \multirow{4}{*}{$\begin{array}{l}28.59 \\
(.000)\end{array}$} & \multirow{4}{*}{0.217} \\
\hline & Necessity of community gardens & 0.355 & 0.067 & 0.288 & $5.301(.000)$ & & \\
\hline & Expectation for community revitalization & 0.257 & 0.062 & 0.234 & $4.175(.000)$ & & \\
\hline & Expectation for increasing visit frequency & 0.096 & 0.049 & 0.111 & $1.970(.050)$ & & \\
\hline \multirow{4}{*}{$\begin{array}{l}\text { Participation in } \\
\text { management }\end{array}$} & (Constant) & 0.398 & 0.318 & & $1.254(.211)$ & \multirow{4}{*}{$\begin{array}{l}41.036 \\
(.000)\end{array}$} & \multirow{4}{*}{0.287} \\
\hline & Necessity of community gardens & 0.486 & 0.069 & 0.362 & $7.010(.000)$ & & \\
\hline & Expectation for community revitalization & 0.219 & 0.064 & 0.183 & $3.429(.001)$ & & \\
\hline & Expectation for increasing visit frequency & 0.173 & 0.051 & 0.182 & $3.398(.001)$ & & \\
\hline \multirow{4}{*}{$\begin{array}{c}\text { Participation in } \\
\text { education }\end{array}$} & (Constant) & -4.851 & 0.712 & & $-6.813(.000)$ & \multirow{4}{*}{$\begin{array}{l}4.370 \\
(.037)\end{array}$} & \multirow{4}{*}{0.283} \\
\hline & Necessity of community gardens & 0.991 & 0.148 & 0.344 & $6.702(.000)$ & & \\
\hline & Expectation for community revitalization & 0.674 & 0.141 & 0.259 & $4.767(.000)$ & & \\
\hline & Expectation for village environmental purification & 0.277 & 0.133 & 0.113 & $2.090(.037)$ & & \\
\hline
\end{tabular}


Table 15. Logistic regression analysis of participation in community gardens

\begin{tabular}{lcccccc}
\hline \multicolumn{1}{c}{ Variables } & $\beta$ & SE & Wald & df & $p$ & Exp(B) \\
\hline Expectation for community revitalization & 0.564 & 0.213 & 7.029 & 1 & .008 & 1.757 \\
Necessity of community gardens & 0.793 & 0.227 & 12.219 & 1 & .000 & 2.209 \\
(Constant) & -3.702 & 1.049 & 12.444 & 1 & .000 & 0.025 \\
\hline
\end{tabular}

Note. $2 L L=209.528$, Cox \& Snell $\mathrm{R}^{2}=0.105$, Nagelkerke $\mathrm{R}^{2}=0.169$, Hosmer \& Lemeshow test chi $^{2}=11.359(\mathrm{df}=7, p=.124)$, Classification accuracy $=82.4 \%$.

\section{Conclusion}

This study is to provide basic data to set guidelines for management of community gardens and thus analyzed factors affecting expectation and participation of urban residents in community gardens. Necessity of community gardens was generally high, especially among residents with an outdoor garden. Those with personal gardening experience are perceiving the need for community gardens as a public space. Expectation was high in terms of the social aspect such as improvement of quality of life, health promotion, and community revitalization by creating community gardens. Residents of individual housing especially had high expectation for community revitalization, which indicates that community gardens may serve as a mediating factor that forms and maintains a local community. This shows the perception of urban residents about the role and function of gardens as a community space. Expectations for improvement of quality of life, health promotion, and community revitalization serve as factors affecting the necessity of community gardens. Residents showed high participation in community gardens from construction to management, and necessity of community gardens, expectation for community revitalization, and expectation for environmental purification are factors that make them participate in management of community gardens. The residents were willing to donate an average of KRW 75,222 per year for community garden management. Overall, those with higher need for community gardens and higher expectation in terms of the social aspect showed higher participation. Urban residents have high expectation for community gardens and are perceiving the importance of the social aspect more than the individual aspect, such as community revitalization and improvement of quality of life. As high expectation for community gardens may lead to high perception on the necessity of community gardens, which may then lead to high participation in community gardens, these factors must be considered in implementing policies regarding community gardens. Participation in community gardens was especially high among women, older age groups, residents of individual housing and people with high expectation, which must also be considered.

Based on the results, the following suggestions can be made regarding strategies for construction and management of community gardens with resident participation. Participation in community gardens may vary depending on perception about community gardens such as necessity and expectation. Thus, it is necessary to first analyze community garden user characteristics and needs. This analysis process may be carried out by setting up the process of community gardens, which is classified into stages of meeting, project and operation. In the meeting stage, plans are made based on regional characteristics such as individual expectations and participation motives. In the project stage, residents are encouraged to participate in creation of community gardens, whereas in the operation stage they are encouraged to participate in management. Ministry of the Interior and Safety, Seoul and Paju are carrying out a support project for community gardens created by resident participation. They require detailed plans such as resident participation and roles in management when applying for the project. Paju is especially building a support system for residents to participate from construction to management such as design, seeding, watering and weeding and to develop their competencies in gardening. The second strategy is to form an organization to operate the process; that is, organize the participants and set up their roles. Since community gardens are public goods, concentrating all the roles on specific participants will result in inequality caused by free riding, and thus community gardens will not be able to last. It is neces- 
sary to allocate roles according to participation motives so that community gardens are systematically operated to meet the expectations of participants. The village gardening project of old and original downtown villages in Daegu established a system for resident participation by organizing a village cooperative association. Third, it is necessary to systemize the means of participation. To manage community gardens in terms of hardware and fulfill various motives, it is necessary to run programs in terms of software. There are different expectations for community gardens depending on user characteristics such as age, residential type and garden experience, and thus there must be programs to fulfill the participation motives of different groups, especially a system for them to actively participate beyond just interest and expectation. Furthermore, considering the welfare aspect such as improvement of quality of life for residents including community revitalization, it is necessary to consider cooperation with specialists and administrative support according to the stages of participation strategies for community gardens. Seoul is building the foundation for community revitalization through public participation projects such as community garden construction and urban greening project in which residents participate through the 'Seoul Blooming' campaign. Community gardens can be maintained with adequate support and cooperation of administrative agencies and specialists along with participation of residents.

Community gardens will be able to secure sustainability by revealing community spirit of members as a place for community activities, and community spirit can be fulfilled when there is confidence about the benefits of community gardens. However, this study determined the awareness of urban residents in participation itself without considering their experience in community gardens. Therefore, further research is required to set the direction for improvement by determining actual user characteristics according to purpose of construction, location and function of community gardens.

\section{References}

Alaimo, K., E. Packnett, R.A. Miles, and D.J. Kruger. 2008. Fruit and vegetable intake among urban com- munity gardeners. J. Nutr. Educ. Behav. 40(2):94-101. https://doi.org/10.1016/j.jneb.2006.12.003

An, Y.W. 2012. Management and civic willingness-to-pay for public parks: For public parks situated in Busan metropolitan city. Doctoral dissertation, Dong-A University, Busan, Korea.

Armstrong, D. 2000. A survey of community gardens in upstate New York: Implications for health promotion and community development. Health Place 6(4):319-327. https://doi.org/10.1016/S1353-8292(00)00013-7

Bell, S., R. Fox-Kämper, N. Keshavarz, M. Benson, S. Caputo, S. Noori, and A. Voigt. 2016. Urban allotment gardens in Europe. Abingdon, UK: Routledge.

Birky, J. and E. Strom. 2013. Urban perennials: How diversification has created a sustainable community garden movement in the United States. Urban Geogr. 34(8):1193-1216. https://doi.org/10.1080/02723638.20 13.784086

Chailse, N. 2015. Collective action dynamics urban neighborhoods: A study of urban community gardens. Doctoral dissertation, Washington University, St. Louis, USA.

Cho, D.H. 2008. A study on plan of resident participation park remodeling. Master's thesis, University of Seoul, Seoul, Korea.

Choi, H.Y. and H.J. Jun. 2017. The relationship between residential mobility and residential satisfaction in the Seoul metropolitan area. J. Korean Urban Manag. Assoc. 30(1):163-180.

Choi, J.M. and B.H. Seo. 2016. Research on developing a model for perry-urban welfare community garden for second-class citizens in the metropolis. J. Resid. Environ. Inst. Korea 14(1):97-116.

Choi, M.H. and M.G. Jeong. 2015. The effect of sense of community on citizen participation. Korean Public Adm. Rev. 49(2):273-306.

Chung, S.K., D.B. Song, and H.J. Im. 2015. The relations on sense of community and local community. J. Reg. Stud. 23(4):103-122. Retrieved from http://www.kars. or.kr

Conway, B.P. and D.S. Hachen, Jr. 2005. Attachments, grievances, resources, and efficacy: The determinants of tenant association participation among public housing 
tenants. J. Urban Aff. 27(1):25-52. https://doi.org/10.1 111/j.0735-2166.2005.00223.x

Drake, L. and L.J. Lawson. 2015. Results of a US and Canada community garden survey: Shared challenges in garden management amid diverse geographical and organizational contexts. Agric. Hum. Values 32(2):241-254. https://doi.org/10.1007/s10460-014-9558-7

Flachs, A. 2010. Food for thought: The social impact of community gardens in the Greater Cleveland Area. Electron. Green J. 1(30):1-9.

Guitart, D., C. Pickering, and J. Byrne. 2012. Past results and future directions in urban community gardens research. Urban For. Urban Green. 11(4):364-373. http s://doi.org/10.1016/j.ufug.2012.06.007

Han, S.W. and B.H. Nam. 2015. The strategy of community activation through the building of village garden facilities. Proceedings of 2015 Winter Conference for the Korean Association for Public Administration (pp. 1636-1646).

Hynes, H.P. and G, Howe. 2004. Urban horticulture in the contemporary United States: Personal and community benefits. Acta Hortic. 643:171-181. https://doi.org/10.17660/ActaHortic.2004.643.21

Irvine, S., L. Johnson, and K. Peters. 1999. Community gardens and sustainable land use planning: A case study of the Alex Wilson community garden. Local Environ. 4(1):33-46. https://doi.org/10.1080/13549839908725579

Jeong, N.R., M.I. Jeong, S.W. Han, and J.S. Kim. 2017. Study on community gardens for village development projects. J. People Plants Environ. 20(1):7-17. https://d oi.org/10.11628/ksppe.2017.20.1.007

Jeong, N.R,, S.W. Han, K.J. Kim, and Y.B. Jung. 2018. Using the perceptions of residents to determine key priorities for planning a community garden. J. East Asian Landsc. Stud. 12(4):25-33.

Jeong, N.R., S.W. Han, K.J. Kim, J.N. Suh, and J.H. Yoon. 2018. Functionality importance and expectation analysis for the planning direction establishment of community gardens. J. People Plants Environ. 21(2):81-91. https://d oi.org/10.11628/ksppe.2018.21.2.081

Jung, S.R. 2017. Mediating effects of sense of community in the relation of neighborhood disorder and depres- sion, life satisfaction among the elderly living alone: Implications for Christian counseling. Theol. Prax. 56:471-492. Retrieved from http://www.praxis.or.kr

Kang, S.M., S.I. Kim, S.K. Shin, E.J. Lim, and W.K. Yoon. 2013. A study on through urban gardening for the activation of community: Focused on service design methodology. J. Digit. Des. [Korean Digital Design Society] 13(3):341-350.

Kim, D.G. 2011. The effect of local community spirit on the behavior of collaborative conflict resolution. Dispute Resolut. Stud. Rev. 9(1):67-93. https://doi.org/ 10.16958/drsr.2011.9.1.67

Kim, H.Y. 2013. Effects of community garden construction and horticultural activities on the life-satisfaction of rural residents. Master's thesis, Chungnam National University, Daejeon, Korea.

Kim, J.Y., Y.S. Kim, and Y.S. Lee. 2013. A study on classification of effect measurements of community garden. J. Korea Inst. Ecol. Archit. Environ. 13(5):23-30. https:// doi.org/10.12813/kieae.2013.13.5.023

Kim, J.Y. and Y.S. Lee. 2013. A study on design direction of community garden in urban deprived area through analysis of psychological and social effects: Targeting on the community garden of Jeonju-si urban regeneration test-bed area. Des. Converg. Study 12(6):83-98. Retrieved from http://www.converge.or.kr

Kim, M.H. 2011. Study on the community garden model utilizing a small vacant space in the urban area. Doctoral dissertation, Chonnam National University, Gwangju, Korea.

Kim, M.H. and D.B. Cho. 2010. The possibility of the community garden utilizing the garden as a shared space in the town development and the effect of the daily scenery formation. Proceedings of 2010 Fall Conference for the Korean Institute of Landscape Architecture (pp. 29-32).

Lee, R.Y. 2009. Sense of community and its relationship with exterior spatial composition in apartment complex. Doctoral dissertation, Jeonnam National University, Gwangju, Korea.

Lim, B.H., K.H. Lee, and N.S. Ji. 2015. A comparative study on the residential environment satisfaction and 
the influential factors on the residential improvement project district and the housing redevelopment project district in Daejeon metropolitan area. J. Korean Urban Manag. Assoc. 28(1):33-51.

Lim, J.S. and G.E. Kim. 2019. Factors affecting sense of community: Comparison of different age groups. J. Humanit. Soc. Sci. 10(3):1773-1788. Retrieved from http://eduasia.kr

Litt, J.S., M.J. Soobader, M.S. Turbin, J.W. Hale, M. Buchenau, and J.A. Marshall. 2011. The influence of social involvement, neighborhood aesthetics, and community garden participation on fruit and vegetable consumption. Am. J. Public Health 101(8):1466-1473. https://doi.org/10.2105/AJPH.2010.300111

Maller, C., M. Townsend, A. Pryor, P. Brown, and L. St Leger. 2006. Healthy nature healthy people: 'Contact with nature' as an upstream health promotion intervention for populations. Health Promot. Int. 21(1):45-54.

McCabe, A. 2014. Community gardens to fight urban youth crime and stabilize neighborhoods. Int. J. Child Health Hum. Dev. 7(3):223-236.

McMillan, D. and D.M. Chavis. 1986. Sense of community: A definition and theory. J. Community Psychol. 14(1):6-23.

Mourao, I., M.C. Moreira, T.C. Almeida, and L.M. Brito. 2019. Perceived changes in well-being and happiness with gardening in urban organic allotments in Portugal. Int. J. Sustain. Dev. World Ecol. 26(1):79-89. https://do i.org/10.1080/13504509.2018.1469550

Nordh, H., T. Wiklund, and E. Koppang. 2016. Norwegian allotment gardens: A study of motives and benefits. Landsc. Res. 41(8):853-868. https://doi.org/10.1080/01 426397.2015.1125457

Oh, J.N. and H.S. Park. 2015. A study on the complex building planning for urban agriculture including the program and space characteristics to activate the local community. J. Korean Living Environ. Syst. 22(3):357-368.

Partalidou, M. and T. Anthopoulou. 2017. Urban allotment gardens during precarious times: From motives to lived experiences. Sociol. Ruralis 57(2):211-228. https://doi.org/10.1111/soru.12117

Poulsen, M.N., K.R.S. Hulland, C.A. Gulas, H. Pham, S.L. Dalglish, R.K. Wilkinson, and P.J. Winch. 2014.
Growing an urban oasis: A qualitative study of the perceived benefits of community gardening in Baltimore, Maryland. Cult. Agric. Food Environ. 36(2):69-82. https://doi.org/10.1111/cuag.12035

Poulsen, M.N., R.A. Ne, and P.J. Winch. 2017. The multifunctionality of urban farming: Perceived benefits for neighbourhood improvement. Local Environ. 22(11):1411-1427. https://doi.org/10.1080/13549839.2017.1357686

Roh, H.Y. 2012. A study on the influencing factors of urban community garden for the activation of community. Master's thesis, Seoul National University, Seoul, Korea.

Saldivar-Tanaka, L. and M.E. Krasny. 2004. Culturing community development, neighborhood open space, and civic agriculture: The case of Latino community gardens in New York City. Agric. Hum. Values 21(4):399-412. https://doi.org/10.1007/s10460-003-1248-9

Schram-Bijkerk, D., P. Otte, L. Dirven, and A.M. Breure. 2018. Indicators to support healthy urban gardening in urban management. Sci. Total Environ. 621:863-871. https://doi.org/10.1016/j.scitotenv.2017.11.160

Scott, A., A. Dean, V. Barry, and R. Kotter. 2018. Places of urban disorder? Exposing the hidden nature and values of an English private urban allotment landscape. Landsc. Urban Plan. 169:185-198. https://doi.org/10.1 016/j.landurbplan.2017.09.004

Winkler, B., A. Maier, and I. Lewandowski. 2019. Urban gardening in Germany: Cultivating a sustainable lifestyle for the societal transition to a bioeconomy. Sustainability 11(3):801. https://doi.org/10.3390/su11030801

Yang, D.S. and Y.S. Kang. 2008. Resident participation raises local community consciousness, which is vital for the success: Jeju Special Self-Governing Province. J. Korean Assoc. Local Govern. Stud. 20(1):71-89.

Yim, J.B. 2005. Regional conflict, citizen participation and governance. J. Korean Assoc. Reg. Inform. Soc. 8(1): 125-151.

Zick, C.D., K.R. Smith, L. Kowaleski-Jones, C. Uno, and B.J. Merrill. 2013. Harvesting more than vegetables: The potential weight control benefits of community gardening. Am. J. Public Health 103(6):1110-1115. https://doi.org/10.2105/AJPH.2012.301009 